\title{
Exposure to benzene in urban workers: environmental and biological monitoring of traffic police in Rome
}

\author{
R Crebelli, F Tomei, A Zijno, S Ghittori, M Imbriani, D Gamberale, A Martini, A Carere
}

National Health

Institute, Rome, Italy

R Crebelli

A Zijno

A Carere

Institute of

Occupational

Medicine, University

"La Sapienza", Rome,

Italy

F Tomei

A Martini

Fondazione Salvatore Maugeri IRCSS,

Pavia, Italy

S Ghittori

Department of

Preventive,

Occupational and

Community Medicine,

University of Pavia,

Italy

M Imbriani

SPRESAL Azienda USL RM/A, Rome,

Italy

D Gamberale

Correspondence to:

Dr R Crebelli, Laboratory of Comparative Toxicology and

Ecotoxicology, Istituto

Superiore di Sanita', Viale

Regina Elena, 299 I-00161

Rome, Italy

crebelli@iss.it

Accepted 14 November 2000

\begin{abstract}
Objectives-To evaluate the contribution of traffic fumes to exposure to benzene in urban workers, an investigation on personal exposure to benzene in traffic police from the city of Rome was carried out.

Methods-The study was performed from December 1998 to June 1999. Diffusive Radiello personal samplers were used to measure external exposures to benzene and alkyl benzenes during the workshift in 139 policemen who controlled medium to high traffic areas and in 63 office police. Moreover, as biomarkers of internal exposure to benzene, blood benzene, and urinary trans, trans-muconic and S-phenyl mercapturic acids were measured at the beginning and at the end of the workshift in $\mathbf{1 2 4}$ traffic police and 58 office police.
\end{abstract}

Results-Time weighted average (TWA) exposure to benzene was consistently higher among traffic police than among indoor workers (geometric mean 6.8 and $3.5 \mu \mathrm{g} / \mathrm{m}^{3}$, respectively). Among the traffic police, the distribution of individual exposures was highly asymmetric, skewed toward higher values. Mean ambient benzene concentrations measured by municipal air monitoring stations during workshifts of traffic police were generally higher (geometric mean $12.6 \mu \mathrm{g} / \mathrm{m}^{3}$ ) and did not correlat with personal exposure values. In particular, no association was found between highest personal exposure scores and environmental benzene concentrations. Among the exposure biomarkers investigated, only blood benzene correlated slightly with on-shift exposure to benzene, but significant increases in both urinary trans, trans-muconic and S-phenylmercapturic acids were found in active smokers compared with nonsmokers, irrespective of their job. Conclusion-The exposure to traffic fumes during working activities in medium to high traffic areas in Rome may give a relatively greater contribution to personal exposure to benzene than indoor sources present in confined environments. Smoking significantly contributed to internal exposure to benzene in both indoor and outdoor workers.

(Occup Environ Med 2001;58:165-171)

Keywords: exposure to benzene; traffic fumes; biomonitoring; traffic police
The contamination of urban air by organic and inorganic toxic pollutants causes concern about the possibility of adverse health effects in resident populations. ${ }^{1-4}$ Among organic pollutants, major consideration is given to benzene, because of its established toxic and leukaemogenic activity in humans. ${ }^{56}$ Vehicle emissions and evaporative losses of gasoline give the greatest contribution to environmental benzene, ${ }^{7}$ which is usually in the range $3-110$ $\mu \mathrm{g} / \mathrm{m}^{3}$ in western cities. ${ }^{8}$ Despite benzene sources primarily contaminating the outdoor environment, the pattern of exposure to benzene in urban residents is complex. Several studies highlighted that personal exposure in indoor environments may exceed both outdoor exposures and ambient benzene concentrations measured at fixed sites. ${ }^{9-12}$ This apparent discrepancy has been tentatively explained by either the contribution of environmental tobacco smoke, a major cause of indoor benzene, ${ }^{13}{ }^{14}$ or the absorption and release of environmental benzene by synthetic furniture and fittings such as linoleum and moquettes. ${ }^{12}$ Most studies used random samples of citizens with mixed activities and exposure profiles, intended to be representative of the whole urban population. However, it is conceivable that exposure to benzene from direct exposure to traffic fumes, as experienced by some categories of outdoor workers, may be considerably higher than the mean exposure of the general population. On the other hand, the relatively high concentrations of exposure for subgroups of urban workers such as policemen, street sweepers, postal workers, and newspaper vendors, should be adequately taken into account in the definition of health risks related to air pollution.

In this study the contribution of the exposure to traffic emissions in the exposure to benzene was assessed in urban workers, in an investigation of exposure to benzene among traffic police in Rome. These workers are professionally exposed to vehicle exhausts while controlling traffic, and they may also be regarded as a model for worst case exposures for urban residents. In this study, about 200 subjects engaged in traffic control or in office work were monitored during the workshift. Passive personal samplers, as well as blood and urinary biomarkers, were used to measure individual exposures to benzene and alkyl derivatives. The intensity of exposure to benzene of the study subjects was also compared with ambient benzene concentrations measured by municipal monitoring stations during the workshift, to 
Table 1 Monitoring of exposure to benzene in outdoor and indoor workers in Rome: main characteristics of the study subjects

\begin{tabular}{lrlll}
\hline Group & $n$ & Sex $(m / f)$ & Age $(y)$ mean $(S D)$ & $\begin{array}{l}\text { Years of employment } \\
\text { mean }(S D)\end{array}$ \\
\hline Traffic police & 139 & $104 / 35$ & $41.5(7.5)$ & $12.3(6.7)$ \\
Office police & 63 & $45 / 18$ & $45.0(7.5)$ & $11.4(6.6)$ \\
Total & 202 & $149 / 53$ & $42.6(7.7)$ & $12.0(6.7)$ \\
\hline
\end{tabular}

investigate the correlation between individual exposure and background concentrations of this pollutant.

\section{Materials and methods}

STUDY POPULATION

Two hundred and two healthy policemen from the city of Rome, Italy, were enrolled in the study. The study population consisted of 139 traffic police engaged in traffic control in three districts with medium to high traffic, selected on the basis of traffic flow data recorded by the Regional Agency for Environmental Protection. Sixty three policemen only involved in office work in the same districts acted as referents. Detailed information on health, smoking, diet, and exposure to aromatic compounds at home or during recreational activities was recorded by questionnaire. Sex distribution, age, and duration of employment of study subjects are shown in table 1. All workers gave informed written consent to participation in the study, which had been authorised by the health authority of the Municipality of Rome.

\section{SAMPLING}

All subjects were monitored once, during the morning shift (0700-1400), on one of 60 working days randomly selected in the period December 1998 to June 1999. To account for environmental or seasonal variations in benzene pollution throughout the study, all measurements (external exposure to volatile hydrocarbons and biomarkers of internal exposure to benzene) were carried out in parallel in traffic police and in office police. Usually two traffic police and one control subject were monitored each day.

MONITORING OF EXTERNAL EXPOSURE TO

VOLATILE AROMATIC HYDROCARBONS

Subjects were equipped with a diffusive air sampler (Radiello, Fondazione S Maugeri, Pavia, Italy), to measure the time weighted average (TWA) concentrations of benzene, toluene, and xylenes in the breathing zone over a 7 hour period. Personal samplers were desorbed with $2 \mathrm{ml}$ benzene free $\mathrm{CS}_{2}$, shaken for 30 minutes and analysed by gas chromatography coupled with mass spectrometry. The detection limit was $0.01 \mu \mathrm{g}$ benzene $/ \mathrm{ml} \mathrm{CS}_{2}$, corresponding to an airborne benzene concentration of $0.7 \mu \mathrm{g} / \mathrm{m}^{3}$.

\section{BIOLOGICAL MONITORING}

Urine and blood samples were collected at the beginning and at the end of the shift. Urine samples were stored in a cooling box until they were returned to the laboratory, where they were divided into several fractions and frozen at $-20^{\circ} \mathrm{C}$.

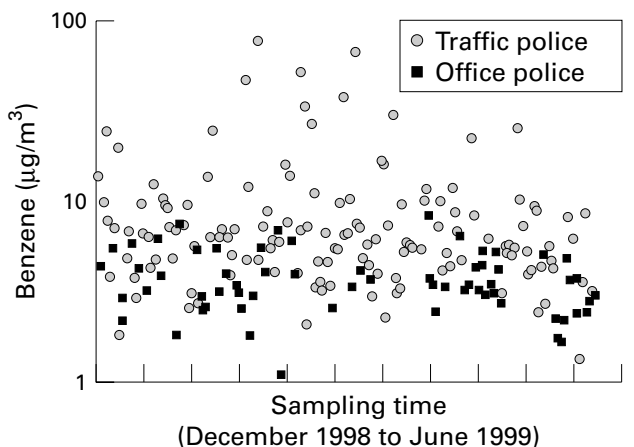

Figure 1 Distribution of exposure concentrations of benzene (7 $h T W A$ ) among traffic police and office police during the study period.

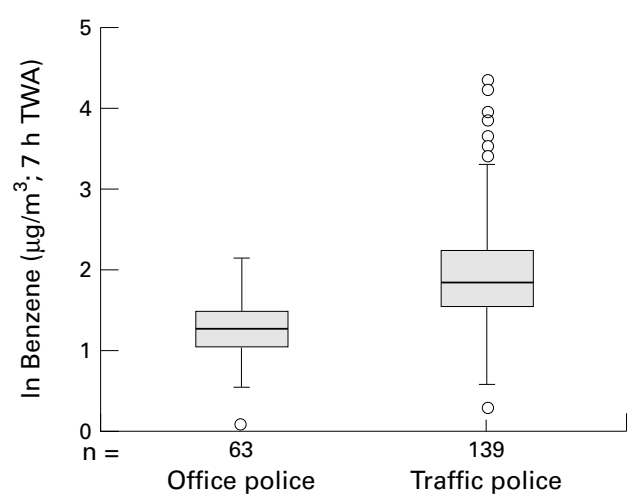

Figure 2 Distribution of concentrations of personal exposure to benzene during the workshift in traffic police and in office police. Each box represents the interquartile range of values with the bold line showing the median value. The vertical lines show the range of values that fall within 1.5 box lengths, the open circles show the outlier values falling between 1.5 and 3 box plot lengths.

S-phenyl mercapturic acid (S-PMA) in urine was measured by high pressure liquid chromatography (HPLC) with a fluorescence detector according to a published method. ${ }^{15}$ The limit of detection was $0.5 \mu \mathrm{g} / 1$. About $25 \%$ of the total urine samples were run in duplicate, with a coefficient of variation of $4.1 \%$. To correct for urine dilution, the results were expressed as $\mu \mathrm{g}$ S-PMA/g creatinine measured by the Jaffé reaction.

Trans, trans-muconic acid (TMA) was measured by HPLC equipped with a UV/VIS detector according to a published method. ${ }^{16}$ The limit of detection was $3 \mu \mathrm{g} / \mathrm{l}$. All urine samples were run in duplicate with a coefficient of variation of $3.4 \%$. The results were expressed as $\mu \mathrm{g} \mathrm{TMA} / \mathrm{g}$ creatinine.

Tenax was used to collect benzene present in blood by diffusion. Blood samples $(5 \mathrm{ml})$ were drawn into glass tubes $(20 \mathrm{ml}$ head space glass vials) containing $50 \mu \mathrm{l}$ heparin as an anticoagulant and containing a sorbent cartridge sheltered with a glass support. The cartridge was filled with $300 \mathrm{mg}$ Tenax (35/50 mesh) previously thermally desorbed to ensure maximum purity. The next day the sorbent cartridges were removed from the tubes and stored in closed vials at $-20^{\circ} \mathrm{C}$ until analysis. Benzene was thermally desorbed from Tenax and injected in a gas chromatograph connected to a flame ionisation detector according to a published method. ${ }^{17}$ The limit of detection was 
Table 2 Occupational exposure and environmental benzene concentrations measured during workshifts of the study subjects

\begin{tabular}{llll}
\hline Benzene $\left(\mu \mathrm{g} / \mathrm{m}^{3}, 7 \mathrm{~h}\right.$ TWA $)$ & $\begin{array}{l}\text { Personal exposure of } \\
\text { traffic police }(n=139)\end{array}$ & $\begin{array}{l}\text { Personal exposure of } \\
\text { office police }(n=63)\end{array}$ & $\begin{array}{l}\text { Environmental } \\
\text { concentrations }\end{array}$ \\
\hline Mean (SD) & $9.3(11.0)$ & $3.8(1.5)$ & $13.1(3.9)$ \\
G mean (SD) & $6.8(2.0)$ & $3.5(1.5)$ & $12.6(1.3)$ \\
Range & $1.3-76.7$ & $1.1-8.3$ & $6.2-24.8$ \\
\hline
\end{tabular}

${ }^{\star}$ Mean of hourly averages measured at four urban monitoring stations for 60 days during 0700 1400 .

Table 3 Pearson's correlation coefficients between benzene and alkylbenzenes: personal exposure measurements and environmental concentrations

\begin{tabular}{llll}
\hline & $\begin{array}{l}\text { Personal exposure } \\
\text { (traffic police) }\end{array}$ & $\begin{array}{l}\text { Personal exposure } \\
\text { (office police) }\end{array}$ & $\begin{array}{l}\text { Environmental } \\
\text { concentrations }^{*}\end{array}$ \\
\hline Benzene $v$ toluene & 0.86 & 0.67 & 0.96 \\
Benzene $v$ ethylbenzene & 0.74 & 0.55 & 0.73 \\
Benzene $v$ m, $p$-xylene & 0.90 & 0.60 & 0.95 \\
Benzene $v o$-xylene & 0.90 & 0.59 & 0.90 \\
\hline
\end{tabular}

${ }^{\star}$ Correlation coefficients between monthly average concentrations measured in Rome at four municipal monitoring stations during July 1998 to April $1999 .^{20}$

$50 \mu \mathrm{g} / \mathrm{l}$ and the coefficient of variation of the methos was $4.7 \%$.

\section{ENVIRONMENTAL BENZENE}

Air quality in the Municipality of Rome is monitored by the Environmental Department (http://www.comune.roma.it/ambiente/aria/) through a network of monitoring stations in various parts of the city, intended to represent urban reality. Each station records weather variables and environmental concentrations of several pollutants, as recommended by national legislation on urban air quality. Benzene is monitored at four stations with different topology, as defined by official technical regulations (Environment Ministry decree 20/5/91) - that is, two high traffic sites, one densely inhabited medium traffic site, and one green area representative of urban background.

For the aims of this study, data (hourly averages) of urban benzene concentrations from December 1998 to June 1999 were made available by the Environmental Department. Mean urban benzene concentration during the workshift was calculated as arithmetic mean of hourly averages (usually 28 measurements, seven for each of four stations). This value was used as a descriptor of environmental benzene pollution during the workshift of each subject.

STATISTICS

As the distribution of raw data significantly deviated from normality, group mean values were compared by the non-parametric Mann-

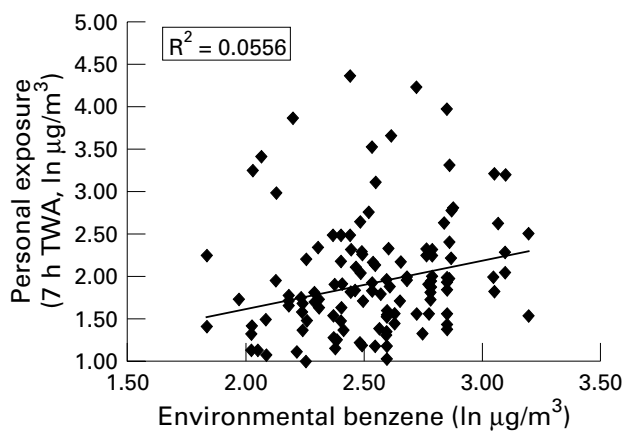

Figure 3 Correlation between personal exposure to benzene of traffic police and environmental benzene concentrations during the workshift.
Whitney $U$ test or by Student's $t$ test after transformation to natural logarithm $(\ln )$. Correlations between $\ln$ transformed experimental data were estimated by Pearson's $r$ coefficient. Stepwise multiple linear regression analysis of ln transformed data was used to estimate the influence of independent variables on personal exposure descriptors. All analyses were performed with the SPSS/PC statistical software package. ${ }^{18}$

\section{Results}

MONITORING OF EXTERNAL EXPOSURE TO VOLATILE AROMATIC HYDROCARBONS DURING THE WORKSHIFT

Time weighted mean concentrations of benzene measured in the breathing zone of traffic police and office police are shown in figure 1 , where individual data are plotted against sampling day. Descriptive statistics of raw data are shown in table 2. Exposure measurements of traffic police showed a higher coefficient of variation (ratio of SD:mean) compared with indoor workers, indicating a wider variation in the exposure profile of traffic police. Individual exposure values of traffic police were distributed over a much wider interval, with a sizeable fraction of values $(42 / 139,30 \%)$ greater than the highest value recorded in office police ( 8.3 $\left.\mu \mathrm{g} / \mathrm{m}^{3}\right)$. Figure 2 shows the distribution of $\ln$ transformed values of exposure to benzene in the two study groups. Values from traffic police and office police were clearly differentiated, with no overlap in the interquartile range. Statistical analysis of data by both parametric and non-parametric tests indicated a highly significant difference in the intensity of exposure to benzene in the two study groups $(p<0.001)$.

As well as benzene, a few alkylated derivatives (toluene, ethylbenzene, $o, m$, and $p$ xylene) were concurrently measured. All aromatic compounds measured were strictly intercorrelated, as expected because of their common origin from antropic sources such as vehicle exhausts. Table 3 shows the correlation coefficients between concentrations of benzene and alkyl benzenes measured in the breathing zone in the two study groups. For comparison, the correlation values between environmental concentrations of the same pollutants measured by the municipal monitoring network between July 1998 and April $1999^{19}$ are also shown. It is stressed that a high intercorrelation between benzene and alkylated benzenes was found throughout the whole group of traffic police, including outliers, thus indicating that the results were not biased by the occasional exposure to other sources of aromatic compoundsfor example, solvents, and paints.

The relation between intensity of personal exposure to benzene and ambient concentrations of this pollutant was also investigated. To this aim, benzene concentrations measured by local air monitoring stations during the study were considered (table 2). As already mentioned (see materials and methods), environmental benzene is measured in Rome at four stations with different topologies, selected to have a representative picture of the overall pollution level in the urban area. The set of data 
Table 4 Occupational exposure to benzene in outdoor and indoor workers: regression analysis

\begin{tabular}{|c|c|c|c|c|}
\hline & $B^{*}$ & $S E$ & $R^{2}$ & $p$ Value \\
\hline \multicolumn{5}{|l|}{ Variablet: } \\
\hline \multicolumn{5}{|c|}{ Dependent variable: ln benzene exposure (whole study population): } \\
\hline Constant $\$$ & -0.593 & 0.403 & & \\
\hline Job & 0.657 & 0.092 & 0.195 & 0.000 \\
\hline Environmental benzene & 0.474 & 0.148 & 0.036 & 0.002 \\
\hline Total & & & 0.231 & 0.000 \\
\hline \multicolumn{5}{|l|}{ Variableł: } \\
\hline \multicolumn{5}{|c|}{ Dependent variable: In benzene exposure (traffic police only): } \\
\hline Constant $\$ & 0.518 & 0.499 & & \\
\hline Environmental benzene & 0.554 & 0.196 & 0.048 & 0.005 \\
\hline Total & & & 0.048 & 0.005 \\
\hline
\end{tabular}

Stepwise regression analysis: for entry $\mathrm{p}=0.05$.

${ }^{\star} \mathrm{B}=$ slope of the regression line.

†Variables considered: job (traffic $v$ office police), environmental benzene, season, smoking habits, sex, age.

†Variables considered: environmental benzene, season, smoking, sex, age.

\Constant $=$ estimated intercept value.

Table 5 Biomarkers of internal exposure to benzene in traffic and office police

\begin{tabular}{|c|c|c|c|c|c|c|c|c|}
\hline & \multicolumn{4}{|c|}{ Traffic police $(n=124)$} & \multicolumn{4}{|c|}{ Office police $(n=58)$} \\
\hline & \multicolumn{2}{|c|}{ Before shift } & \multicolumn{2}{|c|}{ After shift } & \multicolumn{2}{|c|}{ Before shift } & \multicolumn{2}{|c|}{ After shift } \\
\hline \multicolumn{9}{|c|}{ Blood benzene $(\mu \mathrm{g} / \mathrm{l})$ : } \\
\hline Mean (SD) & 178 & (55) & 213 & (111) & 198 & $(180)$ & 195 & (118) \\
\hline G mean (SD) & 170 & (1.4) & 195 & $(1.5)$ & 173 & $(1.5)$ & 176 & (1.6) \\
\hline \multicolumn{9}{|c|}{ Urinary TMA ( $\mu \mathrm{g} / \mathrm{g}$ creatinine): } \\
\hline Mean (SD) & 81 & $(123)$ & 116 & $(236)$ & 72 & $(60)$ & 125 & (138) \\
\hline G mean (SD) & 53 & $(2.2)$ & 65 & $(2.7)$ & 52 & $(2.3)$ & 78 & $(2.7)$ \\
\hline \multicolumn{9}{|c|}{ Urinary S-PMA ( $\mu \mathrm{g} / \mathrm{g}$ creatinine): } \\
\hline Mean (SD) & \multirow{2}{*}{\multicolumn{2}{|c|}{$\begin{array}{l}1.7(1.5) \\
1.3(2.2)\end{array}$}} & \multicolumn{2}{|c|}{$2.6(1.8)$} & \multicolumn{2}{|c|}{$2.2(1.3)$} & \multicolumn{2}{|c|}{$2.8(1.4)$} \\
\hline G mean (SD) & & & \multicolumn{2}{|c|}{$2.1(1.9)$} & \multicolumn{2}{|c|}{$1.8(1.9)$} & \multicolumn{2}{|c|}{$2.5(1.7)$} \\
\hline
\end{tabular}

(hourly means) considered for this work showed a consistent association between measurements taken at the different sites $(r>0.5)$, confirming that data were able to provide reliable information on day to day variation in benzene pollution in the whole urban area, including the districts where the exposure monitoring of traffic police was carried out. The comparison of personal exposure values and environmental benzene concentrations measured concurrently shows a very weak correlation between the two sets of data $\left(R^{2}=0.0556\right.$, ln transformed data). In particular, as shown in figure 3, outlier values of personal exposure did not correspond with episodes of high pollution.

A stepwise regression analysis confirmed that environmental benzene did not contribute to a significant extent to the variability of exposure to benzene of the whole study population, only explaining $5 \%$ of total variance among traffic police (table 4). In this analysis, smoking did not significantly contribute to the variance in external exposure to benzene of the study subjects, suggesting that capture of pollutants by passive dosimeters, which were pinned to the jacket at the level of the heart, was not biased by exhaled tobacco smoke.

Table 6 Correlation coefficients between markers of exposure to benzene

\begin{tabular}{lcll}
\hline & $\begin{array}{l}\text { Benzene } \\
\text { (external exposure) }\end{array}$ & Blood benzene & TMA \\
\hline Blood benzene & 0.17 & & \\
TMA & -0.002 & 0.08 & \\
S-PMA & -0.014 & 0.21 & 0.17 \\
\hline
\end{tabular}

Pearson correlation coefficients between series of ln transformed data from the whole study population (after shift samples).
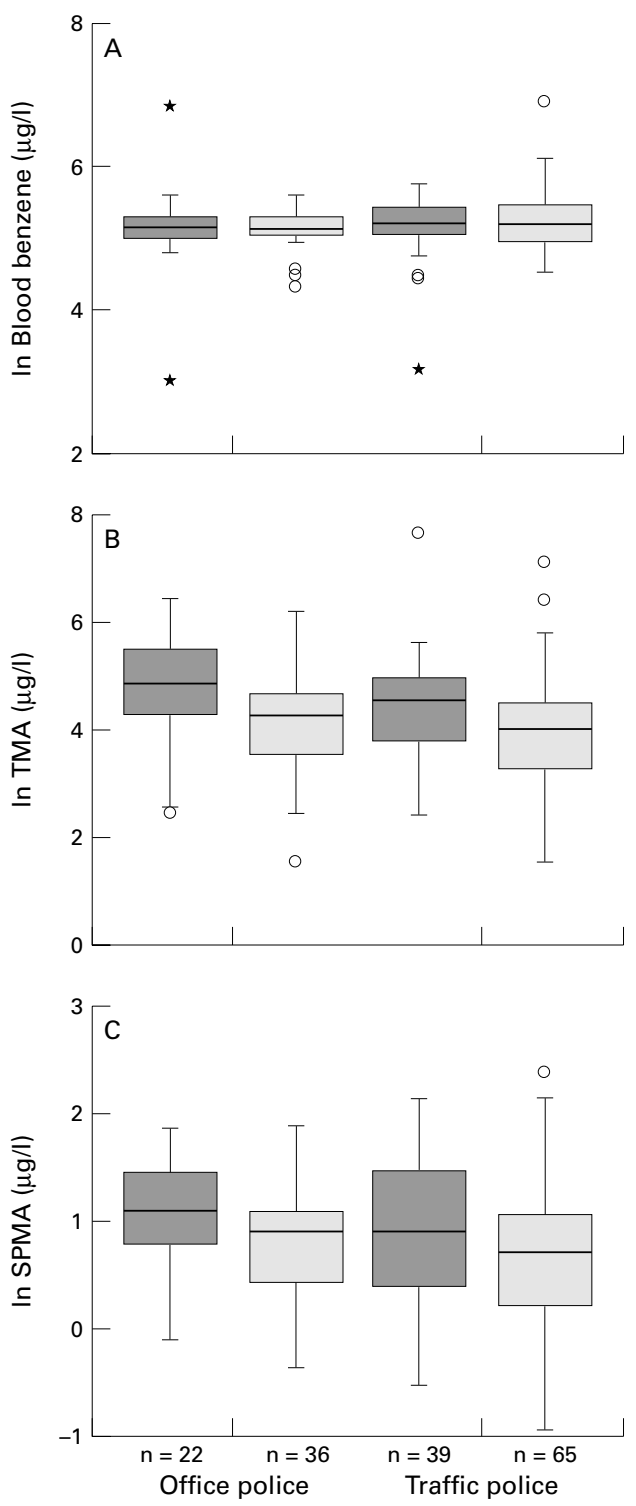

Figure 4 Distribution of values of $(A)$ blood benzene, $(B)$ urinary trans, trans-muconic acid (TMA), and $(C)$ s-phenylmercapturic acid (S-PMA) at the end of workshift in smokers (dark boxes) and non-smokers (light boxes).

Each box represents the interquartile range of values with the bold line showing the median value. The vertical lines show the range of values that fall within 1.5 box lengths, the open circles show the outlier values falling between 1.5 and 3 box plot lengths; asterisks indicate extreme values falling outside 3 box plot lengths. Statistics ( $t$ test on ln transformed data): blood benzene in smokers $v$ non-smokers was not significant for both office police and traffic police, urinary TMA in smokers $v$ non-smokers was $p=0.02$ for office police and $p=0.08$ for traffic police; urinary $S-P M A$ in smokers $v$ non-smokers, $p=0.008$ for office police and $p=0.04$ for traffic police.

BIOLOGICAL MONITORING

All subjects participating in the exposure survey were also enrolled in the biomonitoring study. For technical reasons, all biological samples required (blood and urine before and after the shift) were not available for some subjects. Consequently, full data on biomarkers were only available for 182 subjects (124 traffic police and 58 office police). External exposure of these subjects did not deviate significantly from the whole group (geometric mean (GSD) $6.7(2.0)$ and $3.5(1.5) \mu \mathrm{g} / \mathrm{m}^{3}$ in traffic and office police, respectively). Raw data from the 
analysis of biomarkers of internal exposure to benzene in these subjects are summarised in table 5. No significant differences between traffic police and office police were found for any of the exposure biomarkers sampled at the end of the workshift, also subtracting the values before the shift ( $t$ test on $\ln$ transformed data).

The correlation coefficients of data show that only benzene in blood taken after shift was correlated to some extent with the intensity of on shift exposure to benzene. Urinary biomarkers were not (table 6). This suggests that other factors modulate the variation in urinary TMA and S-PMA in the study population. Smoking is likely to play a part. Both TMA and S-PMA concentrations were significantly higher in smokers than non-smokers $(\mathrm{p}<0.01$, MannWhitney and $t$ test). A similar prevalence of higher values in smokers was also found when comparing separately smokers and nonsmokers among traffic police or office police only (fig 4): despite the small size of the groups, the prevalence of higher concentrations of TMA and S-PMA excreted in smokers was significant $(\mathrm{p}<0.05, t$ test on $\ln$ transformed data) in all but one case (excretion of S-PMA in smoking $v$ non-smoking office police, $\mathrm{p}=0.08, t$ test). On the other hand, no significant difference in blood benzene was found between smokers and non-smokers in the two study groups.

The results of stepwise regression analyses on internal exposure markers are summarised in table 7 . In regression models, blood benzene at the end of the shift was significantly related to the intensity of exposure to benzene during the workshift, whereas increased excretion of TMA and S-PMA was related to smoking. Excretion of S-PMA was also related to blood benzene concentration. Also sex entered the regression models of urinary TMA and S-PMA, which were relatively higher in women. These regression models only explained a small fraction of total variance, suggesting that other, undefined factors play a prevailing part in modulating the internal exposure and excretion of benzene metabolites in the study group.

Table 7 Biomarkers of benzene exposure in urban workers: regression analyses

\begin{tabular}{|c|c|c|c|c|}
\hline & $B^{*}$ & $S E$ & $R^{2}$ & $p$ Value \\
\hline \multicolumn{5}{|l|}{ Variablet: } \\
\hline \multicolumn{5}{|c|}{ Dependent variable: $\ln$ blood benzene (after shift): } \\
\hline Constant $\$$ & 5.057 & 0.084 & & \\
\hline ln TWA benzene exposure & 0.109 & 0.046 & 0.024 & 0.020 \\
\hline Total & & & 0.024 & 0.020 \\
\hline \multicolumn{5}{|l|}{ Variable $\ddagger:$} \\
\hline \multicolumn{5}{|c|}{ Dependent variable: $\ln$ TMA (after shift): } \\
\hline Constant $\$$ & 4.457 & 0.146 & & \\
\hline Smoke & 0.512 & 0.146 & 0.065 & 0.001 \\
\hline Sex & -0.539 & 0.156 & 0.053 & 0.001 \\
\hline Total & & & 0.118 & 0.000 \\
\hline \multicolumn{5}{|l|}{ Variableł: } \\
\hline \multicolumn{5}{|c|}{ Dependent variable: $\ln$ S-PMA (after shift): } \\
\hline Constant $\$$ & -0.671 & 0.555 & & \\
\hline ln blood benzene & 0.293 & 0.102 & 0.038 & 0.005 \\
\hline Smoke & 0.265 & 0.093 & 0.042 & 0.005 \\
\hline Sex & -0.215 & 0.100 & 0.018 & 0.032 \\
\hline Total & & & 0.098 & 0.000 \\
\hline
\end{tabular}

Stepwise regression analysis: for entry $\mathrm{p}=0.05$.

${ }^{\star} \mathrm{B}=$ slope of the regression line.

tVariables considered: TWA benzene exposure, job (traffic $v$ office police), smoking, sex, age.

¥Variables considered: TWA benzene exposure, job, blood benzene, smoking, sex, age.

\Constant=estimated intercept value.

\section{Discussion}

Several large scale studies conducted in Europe $^{1112}$ and in America ${ }^{910}$ indicate that personal exposure to benzene of urban citizens may be significantly higher than mean concentration in urban air, and that concentrations of indoor benzene often exceed the outdoor concentrations. On this basis, it was suggested that non-occupational human exposure to benzene depends principally on indoor air contamination at home and in other confined environments. ${ }^{911}$ On the other hand, wide geographical variation is found in the indoor to outdoor benzene ratio, ${ }^{12}$ suggesting that environmental and meteorological variables can significantly modify the exposure profile of urban residents. In this study of traffic police of the city of Rome, we have investigated the contribution of the exposure to traffic fumes to personal exposure to benzene. Traffic police can be considered as representative of the many urban workers (street sweepers, postal workers, newspaper vendors, etc) exposed to traffic at work, and they have often been selected as a model population to assess the biological effects of exposure to air pollutants in urban areas..$^{20-23} \mathrm{In}$ this work, parallel personal exposure measurements were carried out on traffic police and on policemen from the same districts solely engaged in office work, to disclose the contribution of outdoor activities in high traffic areas to personal benzene burden. Moreover, ambient benzene concentrations measured by municipal monitoring stations during workshifts were considered to investigate the correlation between intensity of personal exposure and environmental benzene concentrations.

The results obtained highlighted a significantly higher mean exposure to benzene in outdoor workers than office police, indicating that direct exposure to traffic fumes contributes more than indoor sources to exposure to benzene. In both outdoor and indoor workers, smoking apparently did not contribute significantly to the external exposure to benzene measured by diffusion passive samplers in the breathing zone.

Concentrations of benzene measured in traffic police showed greater variation than in office police, as was expected of exposure profiles of outdoor workers. In particular, the distribution of personal measurements in traffic police was skewed, with a sizeable fraction of values greater than the highest value measured indoors.

Due to possible differences in the analytical procedures and in the sites of sample collection, no strict quantitative comparison could be made between personal exposure values and concurrent environmental benzene concentrations. However, the data provided by monitoring stations give an indication of the overall daily pollution level in the city which could be compared in relative terms with personal exposure data. Interestingly, this comparison showed an overall weak association between the two sets of measurements, with no parallel rise in environmental benzene coincident with the highest personal exposures of traffic police. This result indicates that outdoor workers may 
occasionally experience relatively high exposures to benzene which are not appreciated by large scale environmental monitoring. Outliers may have resulted from spot sources of high benzene concentrations or unfavourable environmental conditions.

Mean exposure of traffic police to benzene measured in this study was significantly lower than that found in previous studies carried out in other Italian cities, which had fourfold to fivefold higher TWA exposure to benzenes. ${ }^{24} 25$ It is conceivable that these differences mostly reflect the significant decrease in benzene pollution recently found in Rome. ${ }^{196}$ Interestingly, no parallel decrease of other indicators of traffic pollution-for example, carbon monoxide-was found in this city during the same period. ${ }^{19}$ This drop in urban benzene pollution may result from the reduction of benzene content in gasoline (fixed at $<1 \% \mathrm{v}: \mathrm{v}$ from mid-1998), rather than to a decrease in traffic intensity.

In this study, internal exposure to benzene biomarkers were not significantly increased in the group of traffic police compared with indoor workers. Reliable correlations between benzene in the breathing zone and both blood benzene and urinary TMA and S-PMA were mainly found in the thousands of $\mu \mathrm{g} / \mathrm{m}^{3}$ range in occupational settings, ${ }^{27-30}$ and it is likely that these biomarkers lack the sensitivity and specificity required to show very low exposure to benzenes as experienced by the study group. Regression analysis of data showed that only a small fraction of total variance in blood benzene and urinary S-PMA after the shift could be explained by exposure to benzene during the shift. On the other hand tobacco smoke, a well known source of benzene, ${ }^{31} 32$ contributed significantly to urinary excretion of TMA and S-PMA in both study groups (traffic police and office police). The apparent lack of effect of smoking on blood benzene concentrations found in this study is puzzling. This finding may be tentatively explained considering the toxicokinetics of benzene and the different significance of the biomarkers analysed. Due to the fast partitioning of benzene between alveolar air and biological fluids, ${ }^{33} 34$ blood benzene gives an instantaneous measure of exposure, for which sampling time is shown to be critical, $^{35}$ whereas concentrations of urinary metabolites represent time weighted values which may appreciate more easily previous discontinuous exposures related to cigarette smoking. Therefore, even though other studies reported higher blood benzene concentrations in smokers than non-smokers, ${ }^{36}{ }^{37}$ it is possible that the contribution of smoking could not be assessed in this group of municipal workers in which exposure to tobacco smoke during the shift was low as a consequence of current constraints on smoking while on duty.

The regression analysis of individual data on excretion of TMA and S-PMA also showed a significant association with sex, with relatively higher values in women. Differences in internal exposure to benzene between men and women due to physiological and biochemical differences have been reported, with greater blood to air partition and velocity of metabolism for women, ${ }^{38}$ which may account for our results. On the other hand, due to the identical sex ratio in the study groups (traffic police and office police), it is likely that this did not bias our results. Rather, other genetic determinants have been recently shown to modulate the excretion of benzene metabolites, ${ }^{39}$ and they could contribute to the large fraction of unexplained variance.

In any case, the significant increase of urinary TMA and S-PMA found in smokers suggests that the contribution of tobacco smoking to internal benzene load may be at least comparable with exposure to traffic fumes, which did not affect the urinary biomarkers investigated in a detectable way. This result confirms that the efficient delivery of benzene to the receptors makes tobacco smoke a major source of internal exposure to benzene, although only a minor contributor to global pollution. ${ }^{4041}$

We are grateful to Ing Fabio Colombari, from the Agricultural and Environmental Policy Department of the Municipality of Rome, for making available the data on environmental benzene in Rome during the study period, and to Dr Ivano Iavarone, Istituto Superiore di Sanita', for his advice on statistical evaluaIstituto Superiore di Sanita', for his advice on statistical evalua-
tion. This work was partially supported by the Italian Ministry tion. This work was partially supported by the Italian Ministry
for Environment (project PR-22IS). The collaboration of the Municipality of Rome to the study is acknowledged.

1 Watson AY, Bates RR, Kennedy D. Air pollution, the automoWatson AY, Bates RR, Kennedy D. Air pollution, the automo-
bile, and public health. Washington, DC: Health Effects bile, and public health. Washington, DC:

2 Tomatis L. Air pollution and human cancer. Berlin: SpringerVerlag, 1990 .

Verlag, 1990 .
Godlee F. Health and environment. Air pollution I-II. Editorial. BMF 1991;303:1459-61.

4 Katsouyann K, Pershagen G. Ambient air pollution exposure and cancer, Cancer Causes Control 1997;8:28991 .

5 Aksoy M. Benzene carcinogenicity. Boca Raton, FL: CRC Press, 1988.

6 International Agency for Research on Cancer. IARC Monographs on the evaluation of carcinogenic risks to humans. Vol 29. Lyon, France: IARC, 1982.

7 Fishbein L. Benzene: uses, occurrence, and exposure. In: Fishbein L, O'Neill IK, eds. Environmental carcinogens: methods of analysis and exposure measurement. Vol 10. Benzene and alkylated benzenes. Lyon, France: IARC, 1988; Benzene and alkylated benzenes. Lyon,
4:67-108. (IARC Sci Publ No 85.)

8 World Health Organization. Environmental Health Criteria 150. Benzene. Geneva: WHO, 1993.

150. Benzene. Geneva: WHO, 1993 .
9 Wallace LA, Pellizzari ED, Hartwell TD, et al. Personal Wallace LA, Pellizzari ED, Hartwell TD, et al. Personal
exposures to toxic substances in air, drinking water, and breath of 400 residents of New Jersey, North Carolina, and North Dakota. Environ Res 1987;43:290-307.

10 Wallace L. Environmental exposure to benzene: an update. Environ Health Perspect 1996;104(suppl 6):1129-36.

11 Gilli G, Scursatone E, Bono R. Geographic distribution of benzene in air in northwestern Italy and personal exposure. Environ Health Perspect 1996;104(suppl 6): 1137-40.

12 Cocheo V, Sacco P, Boaretto C, et al. Urban benzene and population exposure. Nature 2000;409:141-2.

13 Fishbein L. Exposure from occupation versus other sources. Scand $\mathcal{F}$ Work Environ Health 1992;18(suppl 1):5-16.

14 Wallace LA. The exposure of the general population to benzene. Cell Biol Toxicol 1989;5:297-314.

15 Maestri L, Ghittori S, Grignani E, et al. Measurement in humans of benzene metabolite urinary s-phenylhumans of benzene metabolite urinary s-ph
mercapturic acid (S-PMA), Med Lav 1993;84:55-65.

16 Maestri L, Ghittori S, Fiorentino ML, et al. Measurement of Maestri L, Ghittori S, Fiorentino ML, et al. Measurement of
low levels of urinary trans, trans-muconic acid, Med Lav 199 levels of 86 :40-9.

17 Angerer J, Bader M. Determination of benzene in blood by gas chromatography headspace analysis. In: Imbriani $\mathrm{M}$, Ghittori S, Pezzagno G, et al, eds. Advances in occupational medicine and rehabilitation. Pavia, Italy: Fondazione Salvatore Maugeri Edizioni, 1995.

18 SPSS/PC-V2.0. Base manual. Chicago, IL: SPSS, 1988.

19 Fuselli S, Settimo GV, Viviano G, et al. Concentrazione del benzene nell'aerosol urbano di Roma. Acqua-Aria 1990;10: 867-70.

20 Pallotti G. Rete regionale di rilevamento dell'inquinamento atmosferico. Centro Provinciale di Roma-Relazione 1998. Regione Lazio, Italy: Azienda USL RM/B, 1999.

21 Anwar WA, Kamal AAM. Cytogenetic effects in a group of Anwar WA, Kamal AAM. Cytogenetic effects in a group
traffic policemen in Cairo. Mutat Res $1988 ; 208: 225-31$.

22 Bolognesi C, Gallerani E, Bonatti S, et al. Sister chromatid exchange induction in peripheral blood lymphocytes of traffic police workers. Mutat Res 1997;394:37-44. 
23 Bolognesi C, Merlo F, Rabboni R, et al. Cytogenetic biomonitoring in traffic police workers: micronucleus test in peripheral blood lymphocytes. Environ Mol Mutagen 1997;30:396-402.

24 Chandrasejkaran R, Samy PL, Murthy PB. Increased sister chromatid exchange (SCE) frequencies in lymphocytes from traffic policemen exposed to automobile exhaust pollution. Hum Exp Toxicol 1996;15:301-4.

25 Priante E, Schiavon L, Boschi G, et al. Esposizione agl inquinanti dell'aria urbana dei vigili municipali. Med Lav 1996;87:314-22.

26 Fustinoni S, Buratti M, Giampiccolo R, et al. Biological and environmental monitoring of exposure to airborne benzene and other aromatic hydrocarbons in Milan traffic wardens. Toxicol Lett 1995;77:387-92.

27 Kivisto H, Pekari K, Peltonen K, et al. Biological monitoring of exposure to benzene in the production of benzene and in a cokery. Sci Total Environ 1997;199:49-63.

28 Rupper T, Scherer G, Tricker AR, et al. Trans, transmuconic acid as a biomarker of non-occupational environmuconic acid as a biomarker of non-occupational environ1997;69:247-51.

29 Ong CN, Kok PW, Ong HY, et al. Biomarkers of exposure to low concentrations of benzene: a field assessment. Occup Environ Med 1996;53:328-33.

30 Popp W, Rauscher D, Muller G, et al. Concentrations of benzene in blood and S-phenylmercapturic and $t, t$ muconic acid in urine in car mechanics. Int Arch Occup Environ Health 1994;66:1-6.

31 Fishbein L. Exposure from occupational versus other sources. Scand F Work Environ Health 1992;18(suppl 1):516.
32 Hattemer-Frey HA, Travis CC, Land ML. Benzene: environmental partitioning and human exposure. Environ Res 1990;53:221-32.

33 Perbellini L, Faccini GB, Pasini F, et al. Environmental and occupational exposure to benzene by analysis of breath and blood. Br F Ind Med 1988;45:345-52.

34 Ghittori S, Fiorentino ML, Maestri L, et al. Urinary excretion of unmetabolized benzene as an indicator of benzene exposure. F Toxicol Environ Health 1993;38:233-43.

35 Pekari K, Vainiotalo S, Heikkilä P, et al. Biological monitoring of occupational exposure to low levels of benzene. Scand $\mathcal{F}$ Work Environ Health 1992;18:317-22.

36 Brugnone F, Perbellini L, Romeo L, et al. Benzene in environmental air and human blood. Int Arch Occup Environ Health 1998;71:554-9.

37 Hajimiragha H, Ewers U, Brockhaus A, et al. Levels of benzene and other volatile aromatic compounds in the blood of non-smokers and smokers. Int Arch Occup Environ Health 1989;61:513-18.

38 Brown EA, Shelly ML, Fisher JW. A pharmacokinetic study of occupational and environmental benzene exposure with regard to gender. Risk Anal 1998;18:205-13.

39 Rossi AM, Guarnieri C, Rovesti S, et al. Genetic polymorphisms influence the variability in benzene metabolism in humans. Pharmacogenetics 1999;9:445-51.

40 Perry R, Gee IL. Vehicle emissions and effects on air quality: indoors and outdoors. Indoor Environ 1994;3:224-36.

41 Pezzagno G, Maestri L, Fiorentino ML. Trans, transmuconic acid, a biological indicator to low levels of environmental benzene: some aspects of its specificity. $\mathrm{Am}$ F Ind Med 1999;35:511-18.

\section{Vancouver style}

All manuscripts submitted to Occup Environ Med should conform to the uniform requirements for manuscripts submitted to biomedical journals (known as the Vancouver style.)

Occup Environ Med, together with many other international biomedical journals, has agreed to accept articles prepared in accordance with the Vancouver style. The style (described in full in the $\mathcal{F A M A [ 1 ] )}$ is intended to standardise requirements for authors, and is the same as in this issue.

References should be numbered consecutively in the order in which they are first mentioned in the text by Arabic numerals on the line in square brackets on each occasion the reference is cited (Manson[1] confirmed other reports[2][3][4][5]). In future references to papers submitted to Occup Environ Med should include: the names of all authors if there are three or less or, if there are more, the first three followed by et al; the title of journal articles or book chapters; the titles of journals abbreviated according to the style of Index Medicus; and the first and final page numbers of the article or chapter. Titles not in Index Medicus should be given in full. are:

1 International Committee of Medical Journal Editors. Uniform requirements for manuscripts submitted to biomed journals. $\mathcal{F} A M A$ 1993;269:2282-6.

2 Soter NA, Wasserman SI, Austen KF. Cold urticaria: release into the circulation of histmaine and eosinophil chemotactic factor of anaphylaxis during cold challenge. N Engl F Med 1976;294:687-90.

3 Weinstein L, Swartz MN. Pathogenic properties of invading micro-organisms. In: Sodeman WA Jr, Sodeman WA, eds. Pathologic physiology, mechanisms of disease. Philadelphia: W B Saunders, 1974:457-72. 